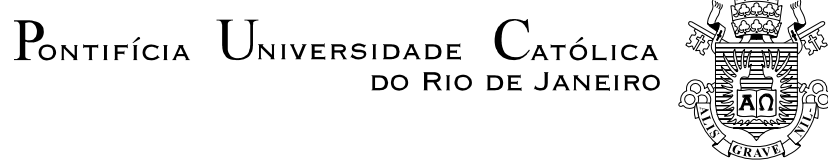

Eduardo Roberto Severino

A teoria da narrativa historiográfica em Tempo e narrativa: uma
contribuição para uma historiografia literária brasileira

Dissertação apresentada como requisito parcial para obtenção do título de Mestre pelo Programa de Pós-Graduação em Letras da PUC-Rio.

Orientador: Prof. ${ }^{a}$ Dra Eliana Lúcia Madureira Yunes Garcia

Rio de Janeiro abril de 2008 


$$
\begin{aligned}
& \text { Pontifícia Universidade Católica } \\
& \text { DO RIO DE JANEIRO }
\end{aligned}
$$

Eduardo Roberto Severino

\section{A teoria da narrativa historiográfica em Tempo e narrativa: uma contribuição para uma historiografia literária brasileira}

Dissertação apresentada como requisito parcial para obtenção do título de Mestre pelo Programa de Pós-Graduação em Letras da PUC-Rio. Aprovada pela Comissão Examinadora abaixo assinada.

Prof. ${ }^{a}$ Dra Eliana Lúcia Madureira Yunes Garcia Orientador PUC-Rio

Prof. Dr Emílio Resende UFMG-BH

Prof. Dr. Paulo César Duque Estrada PUC-Rio

Prof. Paulo Fernando Carneiro de Andrade Coordenador Setorial do Centro de Teologia e Ciências Humanas - PUC-Rio 
Todos direitos reservados. É proibida a reprodução total ou parcial do trabalho sem autorização da universidade, do autor ou do orientador.

\section{Eduardo Roberto Severino}

Licenciou-se em Letras pela Faculdade de Filosofia, Ciências e Letras de Cataguases, Cataguases - MG, em 1994, especializou-se em Língua Portuguesa pela Faculdade de Filosofia, Ciências e Letras Professora Nair Fortes Abu-Merhy, Além Paraíba - MG, em 1998, bacharelou-se e licenciou-se em Filosofia, pelo Centro de Estudos Superiores da Companhia de Jesus, Belo Horizonte - MG, em 2004, e especializou-se em Filosofia Contemporânea pela Pontifícia Universidade Católica do Rio de Janeiro, Rio de Janeiro - RJ, em 2007.

Ficha catalográfica

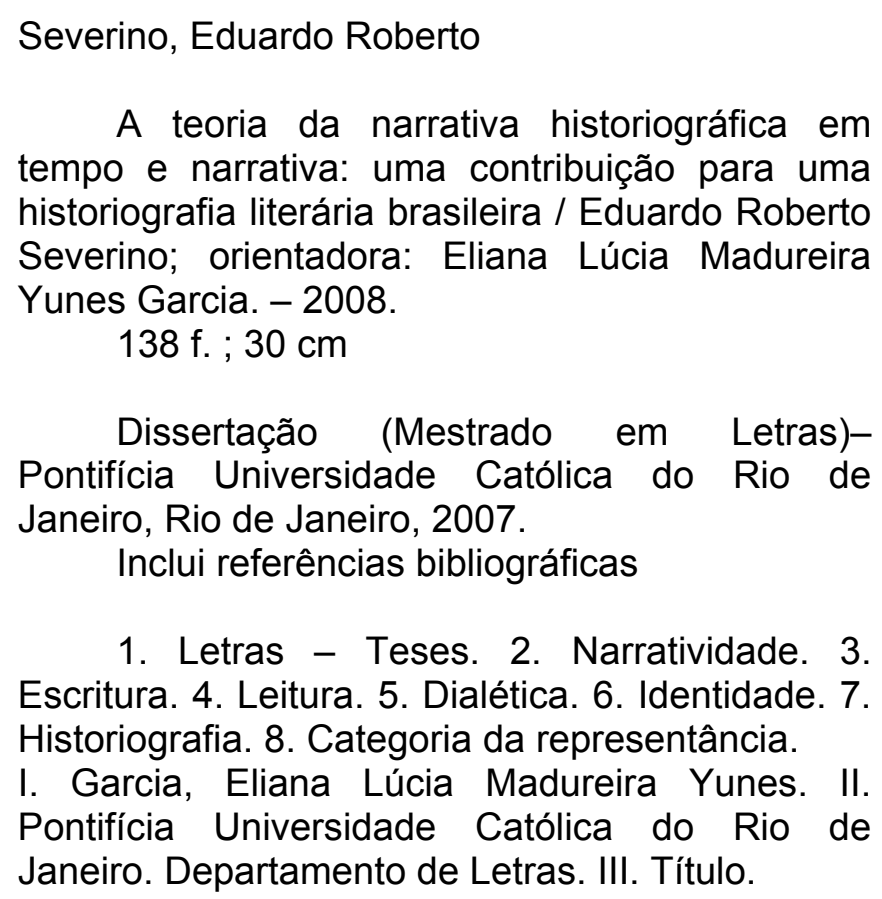

A teoria da narrativa historiográfica em tempo e narrativa: uma contribuição para uma historiografia literária brasileira / Eduardo Roberto Severino; orientadora: Eliana Lúcia Madureira Yunes Garcia. - 2008.

138 f. ; $30 \mathrm{~cm}$

Dissertação (Mestrado em Letras)Pontifícia Universidade Católica do Rio de Janeiro, Rio de Janeiro, 2007. Inclui referências bibliográficas

1. Letras - Teses. 2. Narratividade. 3. Escritura. 4. Leitura. 5. Dialética. 6. Identidade. 7. Historiografia. 8. Categoria da representância.

I. Garcia, Eliana Lúcia Madureira Yunes. II. Pontifícia Universidade Católica do Rio de Janeiro. Departamento de Letras. III. Título. 


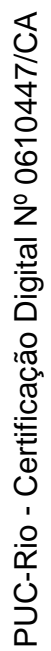

À minha mãe, Aparecida. 


\section{Agradecimentos}

À professora Dra. Eliana Lúcia Madureira Yunes Garcia Yunes, por sua atenciosa orientação.

Aos corpos docente e discente do Departamento de Letras da PUC-Rio, pela partilha do saber.

A CAPES, pelos auxílios concedidos.

Aos meus irmãos jesuítas da Residência Padre Leonel Franca e da Residência João XXIII, pela convivência fraterna.

À família inaciana, pela amizade e pelo apoio cristãos.

À Trindade, que me precedeu, me acompanhou e continua à minha frente, pela providência e generosidade abundantes. 


\section{Resumo}

SEVERINO, Eduardo Roberto. A teoria da narrativa historiográfica em Tempo e narrativa: uma contribuição para uma historiografia literária brasileira. Rio de Janeiro, 2008. 138p. Dissertação de Mestrado - Departamento de Letras, Pontifícia Universidade Católica do Rio de Janeiro.

O objeto estrito de investigação é a identidade narrativa historiográfica, em Tempo e narrativa, de Paul Ricoeur. A hipótese que preside a investigação é a de que a categoria da representância com que Paul Ricoeur nomeia a identidade da narrativa histórica pode ser estendida à identidade narrativa da historiografia literária. O presente trabalho visa à extensão da categoria da representância como identidade da narrativa histórica à identidade narrativa da historiografia literária. Trata-se de uma leitura de Ricoeur... desde Ricoeur... a um problema cotidiano de estudiosos da historiografia literária, sejam alunos, sejam professores, sejam pesquisadores, sejam críticos...: o problema da identidade narrativa da historiografia literária. As partes da dissertação visam levar a termo esse aporte: a categoria da representância como uma resposta plausível para o problema de identidade narrativa da historiografia literária. Uma leitura de Ricoeur... desde Ricoeur... levar-nos-á a nomear a identidade narrativa da historiografia literária brasileira como meio literária meio científica.

\section{Palavras-chave}

Narratividade, escritura, leitura, dialética, identidade, historiografia, categoria da representância. 


\section{Résumé}

SEVERINO, Eduardo Roberto. La théorie du récit historiographique em Temps et récit: une contribuition pour une historiographie litéraire brésilienne. Rio de Janeiro, 2008, 138p. Dissertation de Maîtrise - Départament de Lettres de la Pontificale Université Catholique de Rio de Janeiro.

L'objet strict de cette recherche est l'identité narrative de l'historiographique en Temps et narrative de Paul Ricoeur. L'hypotèse qui oriente cette investigation est celle de la catégorie de la représentance avec laquelle Ricoeur appelle l'identité de la narrative historique qui peut être élargie à identité narrative de 1'historiographie littéraire. Ce présent travail vise 1'extention de la catégorie de la représentance comme identité, partant de la narrative historique jusqu'à l'identité narrative de 1'historiographie littéraire. Il s'agit d'une lecture de Ricoeur... à partir de Ricoeur... s'affrontant à un problème quotidien des étudiants, des élèves, des professeurs, des chercheurs ou des critiqueurs de 1'historiographie littéraire: le problème de l'identité narrative de 1'historiographie littéraire. Les parties de la dissertation cherchent à mener au terme cette contribuition : la catégorie de la représentance comme une réponse plausible au problème de l'identité narrative de 1'historiographie littéraire. Une lecture de Ricoeur... à partir de Ricoeur... mènera à nommer l'identité narrative de l'historiographie littéraire brésilienne comme moyen littéraire moyen scientifique.

\section{Mots-clés}

Narration, écriture, lecture, identité, dialéctique, historiographie, catégorie de la représentance. 


\section{Sumário}

1 A teoria da narrativa historiográfica em Tempo e narrativa: uma contribuição para uma historiografia literária brasileira 14

1.1. Teoria das operações de compreensão de textos 17

1.2. Objeto e itinerário metodológico 19

2 O contar, o compor e o recontar um texto historiográfico como momentos de concordância discordante 23

2.1. A noção de historiografia como texto 24

2.2. A noção de historiografia como tecer da intriga 27

2.3. A noção do fenômeno de concordância discordante 28

2.4. À guisa de conclusão capitular 32

3 Prolegômenos à identidade narrativa de uma historiografia literária brasileira 34

3.1. A linguagem como atos de discurso 35

3.1.1. Unidade dialética do evento e da significação nos atos de discurso36

3.1.1.1. O significado do locutor e o significado da enunciação 36

3.1.2. Unidade dialética do sentido e da referência nos atos de discurso 38

3.1.2.1. O postulado da referência enquanto postulado da linguagem como atos de discurso

3.2. A linguagem como ação: os traços estruturais, simbólicos e temporais da práxis

3.2.1. O fenômeno dos atos do discurso como ação

3.2.2. O fenômeno das ações como tramas: relações de intersignificação43

3.3. A linguagem como escritura

3.3.1. Os fenômenos da escritura como atos de discurso 48

3.3.1.1. O fenômeno da fixação 49

3.3.1.2. O fenômeno da autonomia semântica do texto 51

3.3.1.3. O fenômeno da dialética do endereço 
3.3.1.4. O fenômeno dos expedientes generativos: as obras do discurso53

3.3.1.5. O fenômeno da dialética de segunda ordem 55

3.3.2. O fenômeno de mediação de uma configuração textual 58

3.3.3. O fenômeno da interpretação: a dialética da distanciação e da apropriação $\quad 59$

3.3.4. À guisa de conclusão capitular 63

4 A identidade discursiva da narrativa historiográfica como categoria da representância $\quad 64$

4.1. O modelo de tríplice mimese 69

4.1.1. Mimese I: a pré-compreensão da ação - ato de pré-figuração narrativa $\quad 71$

4.1.2. Mimese II: configuração textual 73

4.1.3. Mimese III: refiguração da experiência temporal 76

4.2. A identidade discursiva da narrativa historiográfica 76

4.2.1. Os ancoradores da historiografia 78

4.2.2. Historiografia como composição textual 81

4.2.2.1. O fenômeno de investigação e explicação histórica 83

4.2.2.2. O fenômeno dos laços de derivação indiretos da operação historiográfica $\quad 86$

4.2.3. A identidade narrativa da historiografia como dialética da representância 90

4.2.3.1. Procedimentos analíticos dissimétricos da narrativa histórica e da $\begin{array}{ll}\text { narrativa ficcional } & 91\end{array}$

4.2.3.2. Relação de complementaridade entre a narrativa histórica e a narrativa ficcional 92

4.2.3.3. Refiguração conjunta: a historiografia como meio literária e meio científica 96

4.3. À guisa de conclusão capitular 98

5 A identidade de uma narrativa historiográfica literária brasileira como meic $\begin{array}{ll}\text { científica e meio literária } & 100\end{array}$

5.1. Os ancoradores da historiografia literária 102

5.2. Historiografia literária como composição textual 105 
5.2.1. O princípio de reconstrução da historiografia literária

5.2.2. O princípio de construção da historiografia literária

5.2.3. O princípio dialético da historiografia literária

5.3. Identidade de uma historiografia literária brasileira como dialética da representância

5.4. À guisa de conclusão capitular

6 Considerações conclusivas

7 Referências bibliográficas 124

7.1. Obras de Paul Ricoeur 124

7.1.1. Livros principais 124

7.1.2. Outros livros 124

7.1.3. Artigos

125 


\section{Abreviaturas}

As referências mais citadas são feitas pelas siglas indicadas abaixo.

\section{Obras}

CI O conflito das interpretações: ensaios de hermenêutica. Tradução de Hilton Japiassu. Rio de Janeiro: Imago, 1978. Título original: Le conflit des interprétations - essais d'herméneutique. Paris: Seuil, 1969.

DA Do texto à acção - ensaios de hermenêutica II. Tradução de Alcino Cartaxo e Maria José Sarabando. Portugal: Rés Editora, s/d. Texto original: Du texte à l'action - Essais d'herméneutique, II. Paris: Seuil, 1986.

DAA O discurso da acção. Portugal: Edições 70, 1988.

II Interpretação e ideologias. Tradução de Hilton Japiassu. Rio de Janeiro: Livraria Francisco Alves, 1977.

MV A metáfora viva. Tradução de Dion Davi Macedo. São Paulo: Edições Loyola, 2000. Título original: La métaphore vive. Paris: Seuil, 1975.

MHO La mémoire, l'histoire, l'oubli. Paris: Editions du Seuil, 2000.

SA O si-mesmo como um outro. Tradução de Lucy Moreira César. Campinas: Papirus, 1991. Título original: Soi-même comme un autre. Paris: Seuil, 1990.

TI Teoria da interpretação. Tradução de Artur Morão. Rio de Janeiro: Edições 70, 1976. Título original: Interpretation Theory: Discourse and the Surplus of Meaning. Fort Worth: Texas Christian University Press, 1976.

TR I Tempo e narrativa I. Tradução de Constança Marcondes Cesar. Campinas: 
Papirus, 1994. Título original: Temps et récit-tome 1. Paris: Seuil, 1983.

TR II Tempo e narrativa - Tomo II. Tradução de Marina Appenzeller. Campinas: Papirus, 1995. Título original: Temps et récit - La configuracion dans le récit de fiction - Tome II. Paris: Seuil, 1984.

TR III Tempo e narrativa - Tomo III. Tradução de Roberto Leal Ferreira. Campinas: Papirus, 1997. Título original: Temps et récit - Le temps raconté Tome III. Paris: Seuil, 1985. 
“... a literatura seria incompreensível para sempre se não viesse a configurar o que, na ação humana, já figura." (TN I, 101)

"Da mesma maneira que a gramática de uma língua regula a produção de frases bem formadas, cujo número e cujo conteúdo são imprevisiveis, uma obra de arte - poema, drama, romance - é uma produção original, uma existência nova no reino da linguagem." (TN I, 109) 